\title{
Experimental research on hydroelastic behaviour of a tank model subdivided into liquid-filled compartments
}

\author{
Kazimierz Trębacki, Ph. D. \\ Gdansk University of Technology
}

\begin{abstract}

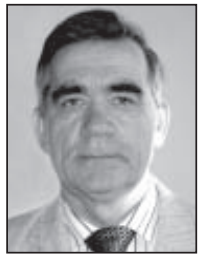

The research was performed with the use of plexiglass models subdivided into 12 separate compartments. The compartments can be filled with a liquid. The model was excited to vibrations within a given frequency band by means of an exciter and accelerations were measured in selected points of the model. During measurement series oscillograms were obtained for various filling states at continuously changing range of measured frequencies. The oscillograms obtained for free vibrations measured on liquid-filled tank models were then processed. Results of the model tests were compared with those theoretically calculated for simple cases of tank-liquid system. The simple cases were used to test correctness of the elaborated computational program for determining hydrodynamic loads applied to tank walls. The application program for determining hydrodynamic internal loads was elaborated. Also, the influence of liquid filling state on values of loading, accelerations and wall deformations was demonstrated.
\end{abstract}

Keywords: vibrations, hydroelasticity, modelling, ship tanks for liquid

\section{INTRODUCTION}

The research concerns an internal hydroelasticity problem and is devoted to experimental vibration tests on a model of liquid - filled tank. It constitutes a continuation of other work where motion of liquid inside the tank has been taken into account. The research deals with transverse vibrations in vertical plane of the liquid - filled deformable tank. Oscillograms were obtained for dry model (free of liquid) as well as the model fully filled with liquid. Next, the oscillograms were processed with respect to vibration of the model within the measuring frequency range.

\section{CHOICE OF A KIND OF ANALYSIS}

The crucial problem in measuring is to determine a kind of frequency analysis which fits the best to a character of vibrations to be measured. Generally, signals which contain discrete frequency components, signals of vibrations which occur in extremely unfavourable conditions as well as spectral density measurements are most correctly analyzed by narrowband filters of a constant bandwidth, whereas broad-spectrum vibrations including system's resonance are analyzed best by means of filters of a constant relative bandwidth.

Choice of analyzed bandwidth is a compromise between required accuracy and duration time of analysis - generally, the smaller bandwidth the longer time necessary to ensure a reasonable accuracy. Application of a real-time analyzer would reduce duration time of the analysis to a minimum but its dynamic range is usually somewhat smaller than that of other kinds of frequency analyzers.

Another choice is also possible: in which case to use a linear mode of frequency tuning, and when logarithmic one. The linear frequency tuning is more favourable when harmonic components of a given frequency are searched for; in the remaining cases application of the logarithmic frequency tuning is more favourable.

To the analysis with constant relative bandwidth the logarithmic frequency tuning is always applied.

The relative bandwidth is defined by the following formula:

where:

$$
\mathrm{f}_{\mathrm{w}}=\frac{\mathrm{f}_{\mathrm{g}}-\mathrm{f}_{\mathrm{d}}}{\mathrm{f}_{\mathrm{o}}}
$$

$\mathrm{f}_{\mathrm{g}}-$ upper band frequency

$\mathrm{f}_{\mathrm{g}}^{\mathrm{g}}-$ lower band frequency

$f_{0}-$ mid-frequency calculated as the mean geometrical value of lower and upper frequencies:

$$
\mathrm{f}_{\mathrm{o}}=\sqrt{\mathrm{f}_{\mathrm{d}}} \cdot \mathrm{f}_{\mathrm{g}}
$$

The relative bandwidth of analyzers is of a value within the range from $1 \%$ to $23 \%$. In the logarithmic tuning their bandwidth is constant and in the linear tuning their bandwidth is proportional to the mid-frequency:

$$
\mathrm{B}=\mathrm{n} \% \mathrm{f}_{\mathrm{o}}
$$


Constant frequency bandwidth analyzers have the following bandwidths: $3.16 \mathrm{~Hz}, 10 \mathrm{~Hz}, 31.6 \mathrm{~Hz}, 100 \mathrm{~Hz}, 316 \mathrm{~Hz}$ i 1000 $\mathrm{Hz}$. In the linear tuning widths of the bands are constant, and in the logarithmic one their widths decrease in a logarithmic scale along with frequency increasing.

\section{CHOICE OF MEASUREMENT PARAMETERS}

Accuracy of measurement results depends on an assumed period of the averaging of speed of recorder tape tracking and strip velocity (of recorder response), width of a measured band and filter response time.

For instance, too short averaging time would not ensure statistically reliable samples of random signal, and too small writting velocity would cause that recording pen would fall behind with appropriate changing the signal, and this way its ups and downs could be lost. A longer averaging time would give a statistically better accuracy, but of course time of analysis would be longer. Excessively large writting speed can often lead to an undesirable fluctuation of a recorded signal level, which otherwise could be damped. As time of analysis and its accuracy are mutually conflicting it should be carefully considered which aspect is more important in a considered case.

In order to reduce the measurement amplitude accuracy of $\pm 1 \mathrm{~dB}$ and frequency shift by $1 / 4$ filter band, the following procedure should be assumed in determining the measurement parameters.

The filter bandwidth $B$ and filter response time $T_{R}$ are mutually dependent according to the following formula:

$$
\mathrm{B} \mathrm{T}_{\mathrm{R}} \approx 1
$$

The filter response time $T_{R}$ determines the filter tuning time $T_{D}$ :

$$
\mathrm{T}_{\mathrm{D}} \geq 4 \mathrm{~T}_{\mathrm{R}}
$$

From the formulas (4) and (5) the relation between the bandwidth of analyzed frequencies and the tuning time of the bands is achieved:

$$
\mathrm{B} \mathrm{T}_{\mathrm{D}} \geq 4
$$

From the relation (6) results that if to extend bandwidth of analyzed frequency the filter tuning time can be shortened at the same measurement accuracy maintained, and this way the whole measurement process can be accelerated.

For random signals the following should be assumed to obtain the accuracy of $\pm 1.5 \mathrm{~dB}$ :

$$
\mathrm{B} \mathrm{T}_{\mathrm{D}} \geq 10
$$

and to obtain the accuracy of $\pm 0.6 \mathrm{~dB}$ :

$$
\mathrm{B} \mathrm{T}_{\mathrm{D}} \geq 50
$$

The signal averaging time can be determined by using the following formula:

$$
\mathrm{T}_{\mathrm{A}} \leq 1 / 2 \mathrm{~T}_{\mathrm{D}}
$$

There are available ready-to-use diagrams from which the tuning time $T_{D}$, signal averaging time $T_{A}$, and tuning rate $\mathrm{S}=\mathrm{B} / \mathrm{T}_{\mathrm{D}}$ can be promptly determined for measurements of both determinate and random signals.

\section{MEASURING SYSTEM}

Schematic diagram of the measuring system is presented in Fig. 1.

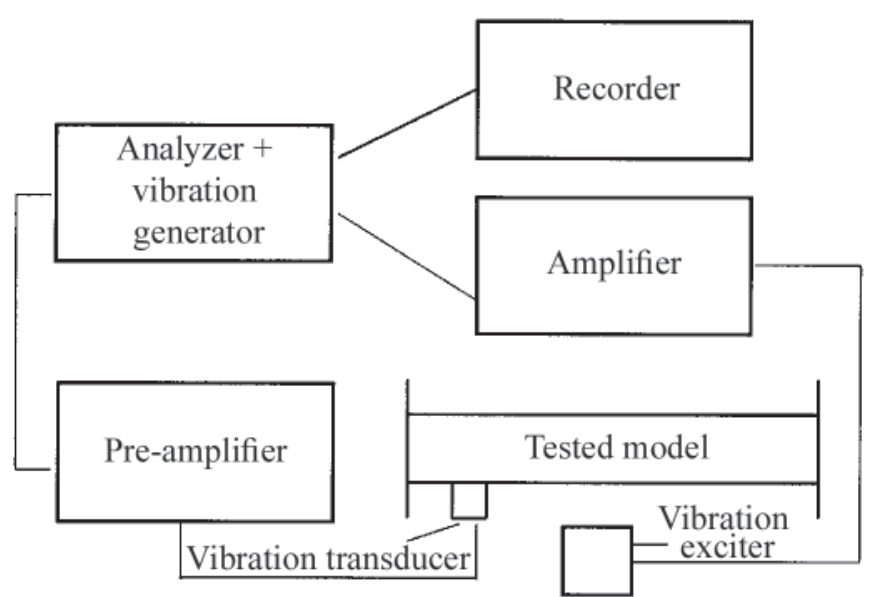

Fig. 1. Schematic diagram of measuring system

The measuring system consists of 2010 Brüel-Kjaer analyzer fitted with beat-frequency generator. Measurements of vibrations at a given frequency is synchronized with that excited.

The so generated signal is transmitted to the amplifier. The amplified signal is transmitted from the amplifier to the electrodynamic exciter of vibrations. The exciter's core connected with the model by means of a clamping ring, excites the model to vibrations in the frequency band of $63 \mathrm{~Hz} \div 6300 \mathrm{~Hz}$.

Vibration accelerations are measured by means of 4324 Brüel-Kjaer piezo-electric transducer. The signal is transferred to 2625 Brüel-Kjaer pre-amplifier, and next to the 2010 analyzer. The so measured quantities expressed in $g-$ units are then saved by using a recorder.

\section{MODEL OF TANK SUBDIVIDED INTO COMPARTMENTS}

The model was made of $2 \mathrm{~mm}$ plexiglass plates. Its dimensions were: $1340 \mathrm{~mm}$ in length, $204 \mathrm{~mm}$ in breadth and $120 \mathrm{~mm}$ in depth. The model was subdivided by a few transverse bulkheads and one longitudinal bulkhead in its plane of symmetry. This way 12 compartments were formed. The model was rigidly connected with a structure made of $200 \times 70 \times 8$ channel bar and loaded by metal plates. The full weight of the model fixing structure amounted to about $200 \mathrm{kG}$. The model was fastened to the metal structure by means of thirteen M12 bolts.

The model and the way of its fastening is presented in Fig. 2 and Photos 1 and 2.

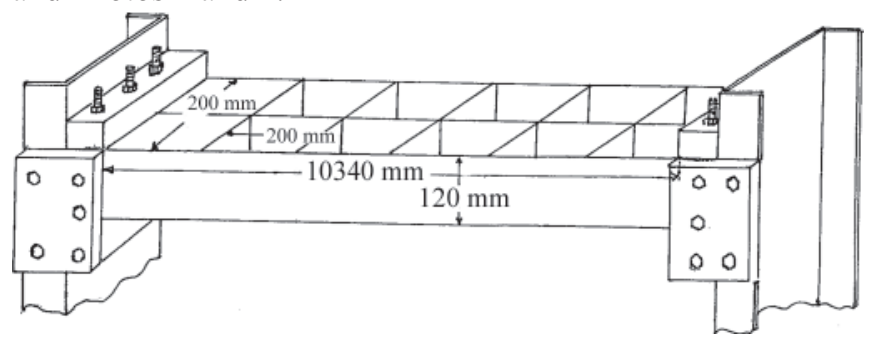

Fig. 2. Draft of the model and way of its fastening

\section{MEASUREMENTS CARRIED OUT ON THE TANK MODEL AND THEIR RESULTS}

The measurements were performed in three characteristic points: 1 - in the middle of the side bulkhead of the first compartment counting from the model mid-length; 2 - in the middle of the bottom of the same compartment; 3 - in the 
connection of the compartments $170 \mathrm{~mm}$ distant from the midlength (see Fig. 2 - shaded compartment).

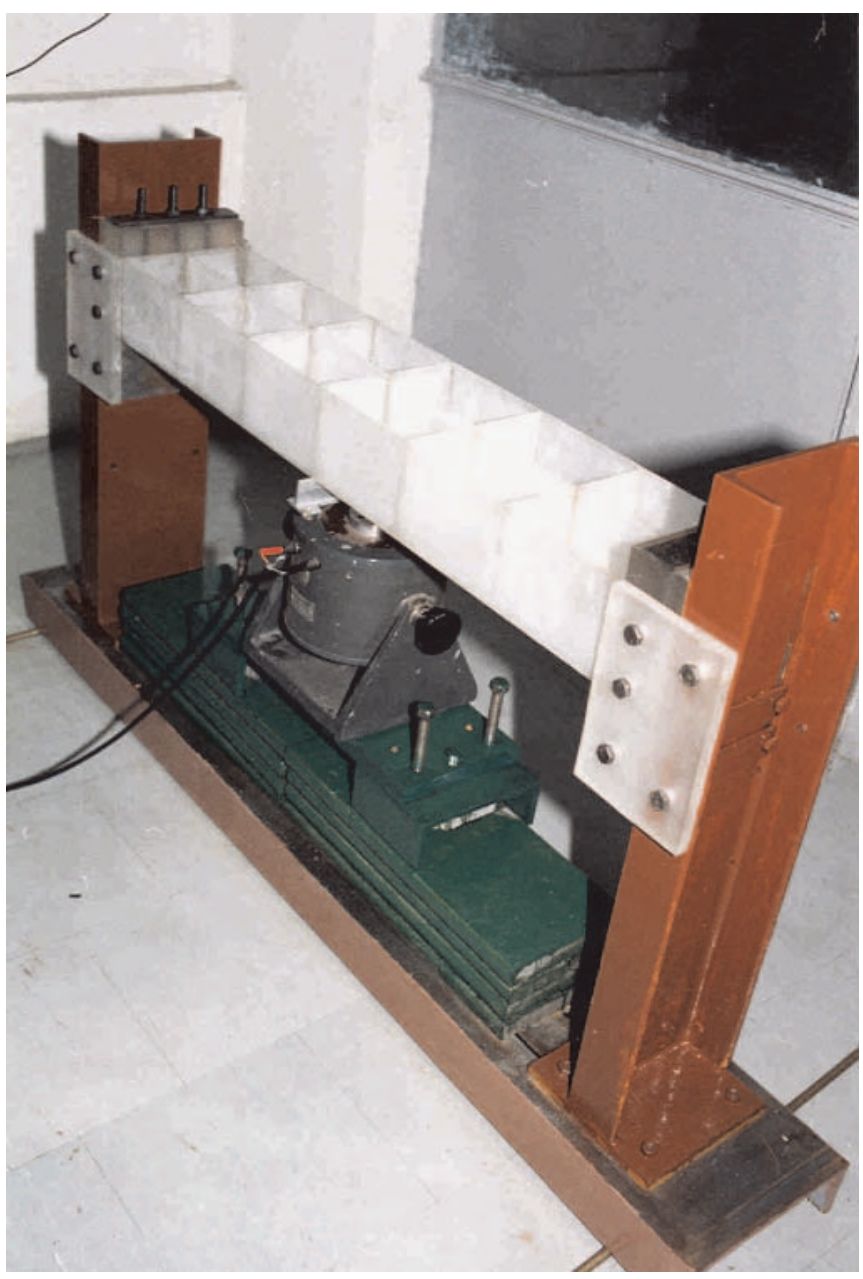

Photo 1. Overall view of the testing installation

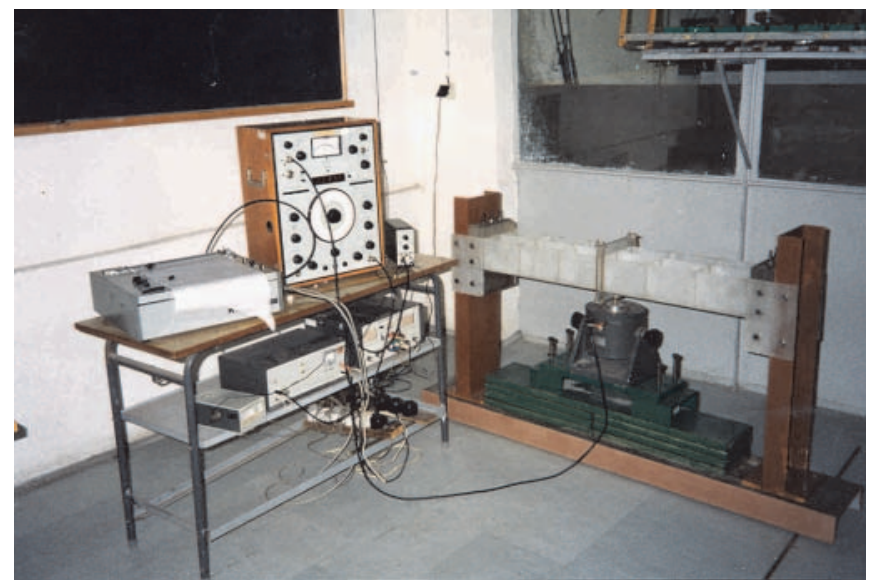

Photo 2. The tested model connected with vibration exciter

The measurements were performed for the empty model and that with all the compartments filled with water. The influence of the water on vibration damping is shown in Fig. 3 through 8 . In each case the amplification of the exciter fixed by means of the clamping ring in the middle of the model,

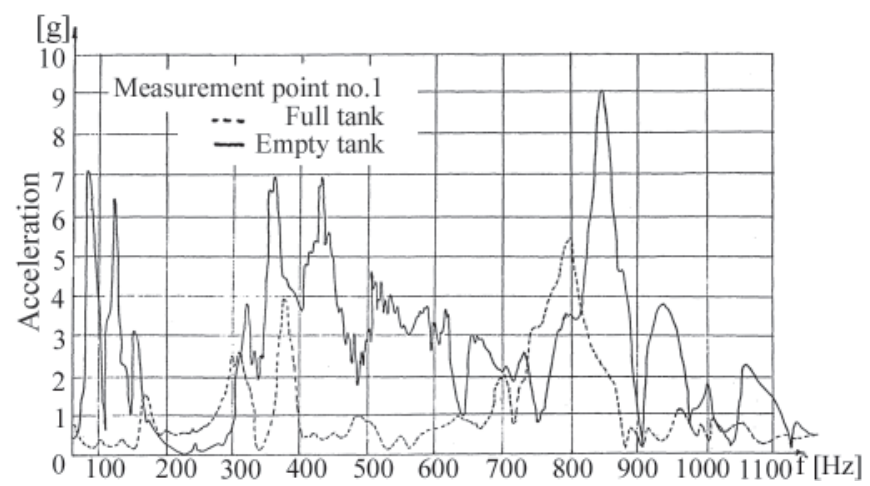

Fig. 3. Run of vibrations at the measuring point 1

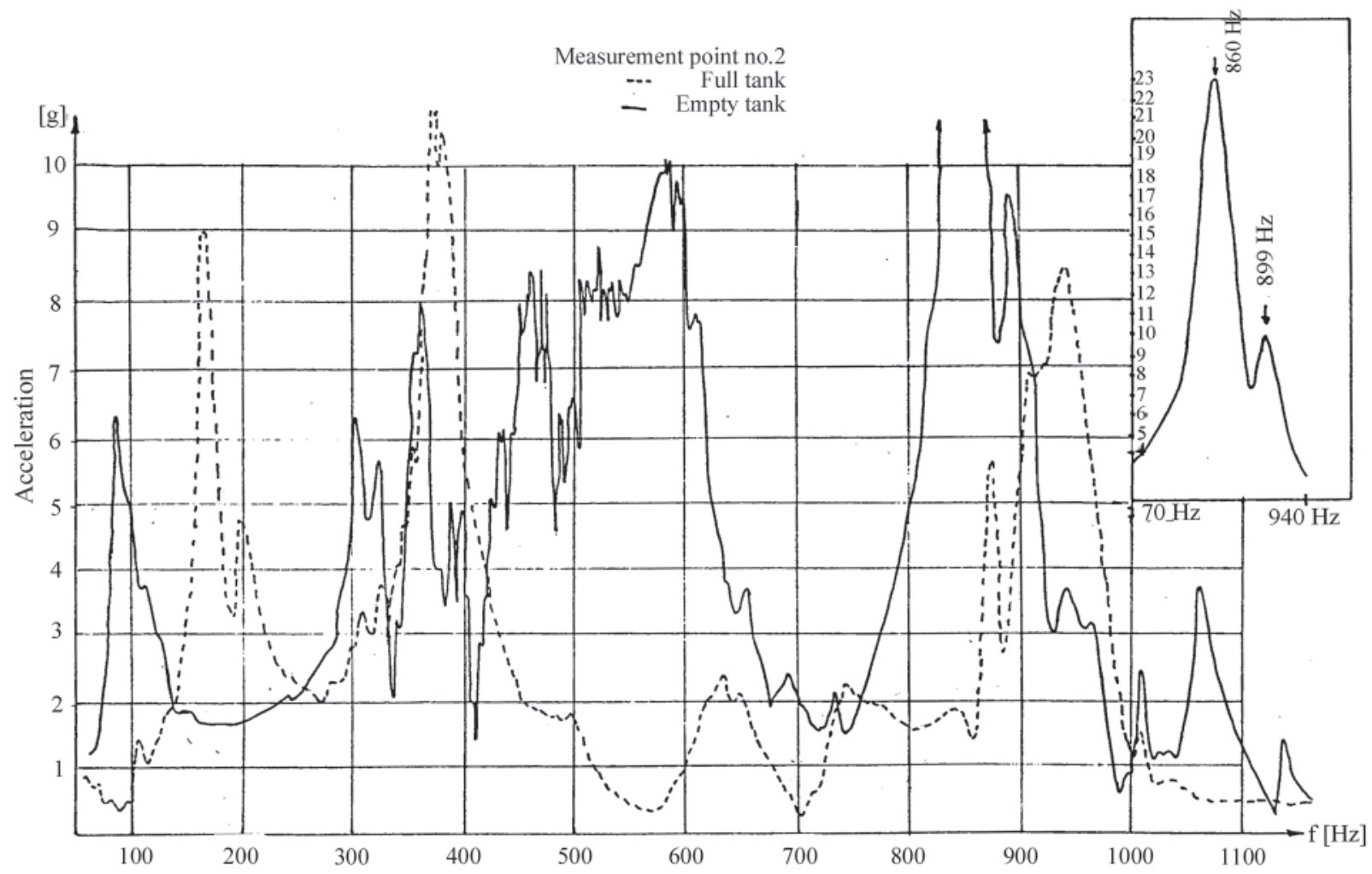

Fig. 4. Run of vibrations at the measuring point 2 
was the same. Comparing the vibrations in the points 1,2 and 3 one can state that character of the vibrations in the points 1 and 2 decisively differ from those in the point 3 . The form of
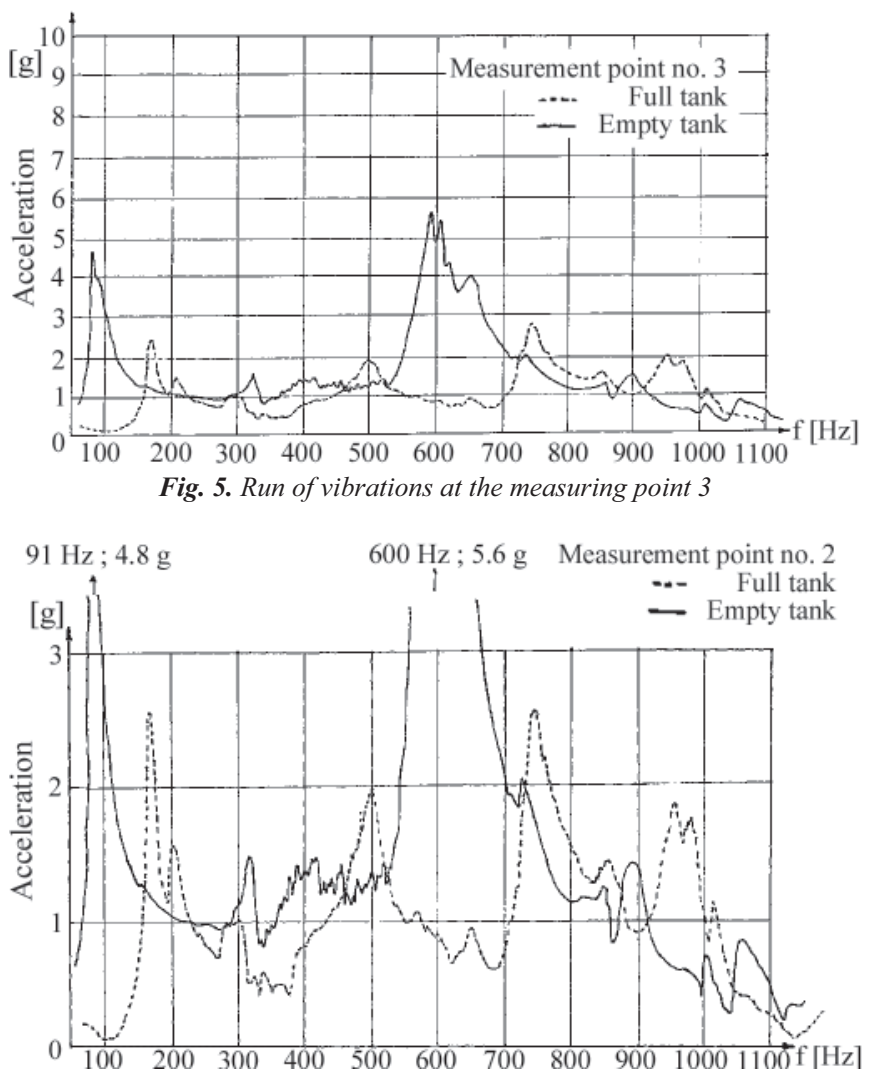

Fig. 6. Vibration spectrum at the measuring point no. 2

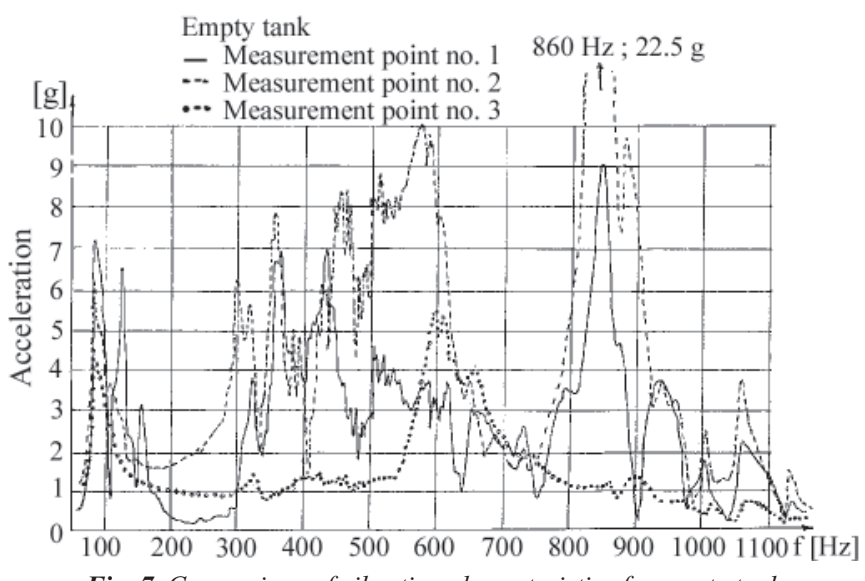

Fig. 7. Comparison of vibration characteristics for empty tank

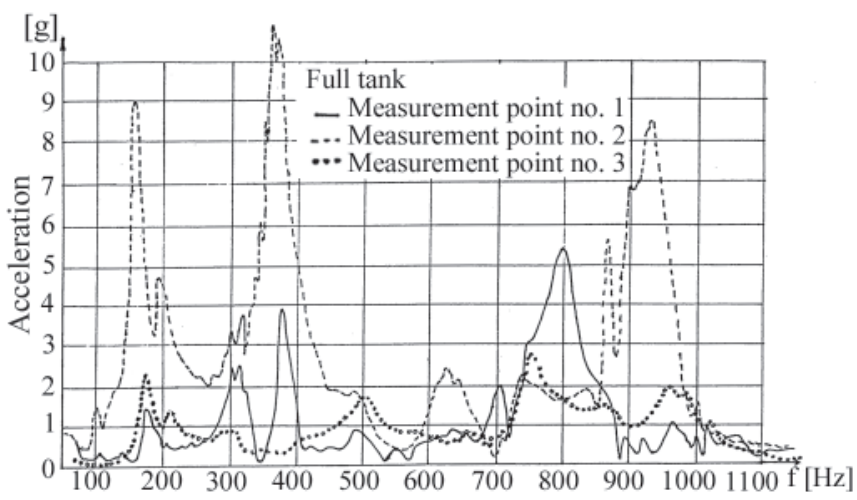

Fig. 8. Comparison of vibration characteristics for tank full of liquid vibration spectrum in the points 1 and 2 of the empty model is influenced mainly by excitation of the bulkheads considered as plates, especially in the frequency range from $300 \mathrm{~Hz}$ to $700 \mathrm{~Hz}$. The vibrations became damped after filling the tank with water. To determine vibration resonance frequency of the model considered as a beam the diagrams shown in Fig. 7 and 8 should be compared.

The measuring system used for the above presented measurements has been already described. To recording of their results a compensatory recorder of Carl Zeiss Jena was applied. Result analysis was carried out for frequencies linearly selected from the range of $60 \mathrm{~Hz} \div 1100 \mathrm{~Hz}$, and for $10 \mathrm{~Hz}$ filtering band (Photo 2).

\section{CONCLUSION}

The performed work makes it possible to verify theoretical analysis by means of results of experimental tests on laboratory models. The results may be useful for designers constructors and users of ship and offshore structures in sea conditions.

\section{NOMENCLATURE}

B - filter width

$f_{d}$ - lower band frequency

$\mathrm{f}_{\mathrm{g}}$ - upper band frequency

$f_{o}$ - mid- frequency of band

$\mathrm{P}^{\circ}$ - recorder tape stracking speed

$\mathrm{S}$ - tuning rate

$\mathrm{T}_{\mathrm{A}}$ - averaging time

$\mathrm{T}_{\mathrm{D}}-$ filter tuning time

$\mathrm{T}_{\mathrm{R}}^{\mathrm{D}}$ - filter response time

\section{BIBLIOGRAPHY}

1. Bathe K.J.: Finite Element Procedure in Engineering Analysis. Prentice Hall, New Jersey, 1982

2. Roliński Y.: Resistance extensometry (in Polish).WNT (Scientific Technical Publishing House), Warsaw 1981

3. Styburski W.: Extensometric transducers (in Polish). WNT (Scientific Technical Publishing House), Warsaw 1971

4. Trębacki K.: Hydrodynamic loads on ship and offshore structures filled with liquid (in Polish), Part I and II, Research reports No. 52/99 and 53/99, Faculty of Ocean Engineering and Ship Technology, Gdańsk University of Technology, Gdańsk 1999

5. Trębacki K.: Free vibrations of a deformable tank filled with liquid (in Polish). Technika Morska (Marine Technology), Vol. I, p. 173-192, Polish Academy of Sciences, Gdańsk 1989

6. Trębacki K.: Selected problems of hydroelastic behaviour of tanks filled with liquid (in Polish). Research report No.14/02/ BW, Faculty of Ocean Engineering and Ship Technology, Gdańsk University of Technology, Gdańsk 2002

7. Zienkiewicz O.C., Bettes P.: Fluid-structure dynamic interaction and wave forces. An introduction to numerical treatment. Int. J. for Num. Meth. in Eng., 13, 1, 1-76, 1978.

\section{CONTACT WITH THE AUTHOR}

Kazimierz Trębacki, Ph. D.

Faculty of Ocean Engineering and Ship Technology

Gdansk University of Technology Narutowicza 11/12

80-952 Gdansk, POLAND

e-mail : katre@pg.gda.pl 